\title{
Optimization of Shell and Tube Condenser for Low Temperature Thermal Desalination Plant
}

\author{
Elakkiyadasan $\mathrm{R}^{1}$, Manoj Kumar $\mathrm{P}^{1}$, Subramanian $\mathrm{M}^{1^{*}}$ Balaji $\mathrm{N}^{2}$, Karthick $\mathrm{M}^{3}$ and Kaliappan $\mathrm{S}^{4}$ \\ ${ }^{1}$ Assistant Professor, St.Joseph's College of Engineering, Chennai, Tamilnadu-600119, India \\ ${ }^{2}$ Professor, Saveetha Engineering College, Chennai, Tamilnadu-602105, India \\ ${ }^{3}$ Assistant Professor, Velammal Engineering College, Chennai, Tamilnadu-600066, India \\ ${ }^{4}$ Associate Professor, Velammal Institute of Technology, Chennai, Tamilnadu-602104, India \\ *Corresponding author: elakkiyadasanr@stjosephs.ac.in
}

\begin{abstract}
In the current work, attempt for enhancing the heat exchanger of the shell and tube by analyzing the various parameters. The heat exchanger is a device used to transfer heat between at least two fluids. In the different kinds of heat exchangers utilized in various industries, shell and tube heat exchangers are presumably the most adaptable and widely heat exchangers utilized in most industrial areas. Based on the relationship between different parameters such as tube velocity, overall heat transfer coefficient, mass flow rate, and pumping power, analysis is carried out. Results show that the tube velocity increases the overall heat transfer coefficient, total pressure drop and mass flow rate of water, Pumping Power, up to the certain limit and starts to decrease. So that the parameters can be optimized by conducting the experiments based on different input parameters. The parameters which influence the optimal result are researched and recommended.
\end{abstract}

\section{Introduction}

Sea water desalination is achieving extending thought of present-day technique makers, especially with the making demands that development, masses impact, inconsistent precipitation and ground water contamination on the delicate standard resources [1]. Low temperature thermal desalination is one system that uses the availability of a temperature incline between two water bodies [2], the oceans thermal gradient that depicts temperature variety over the significance of the oceans, to gain new water. The open heat slant between more intense surface water and colder significant seawater is utilized by streak evaporating [3].The LowTemperature Thermal Desalination (LTTD) plant runs on the rule of flash purifying by evaporating heat surface seawater in a chamber kept up under and therefore melting the subsequent fume in a condenser [4]. A Shell and Tube heat exchanger, in which $12^{\circ} \mathrm{C}$ remote ocean cold water streams inside cylinder group, was chosen considering its different points of interest, for example, low-pressure drop, multi-tube pass course of action, simple support and Rugged mechanical development [5]. The exchanger contains $\mathrm{Cu}-\mathrm{Nickel}$ tubes encased inside a SS-304L shell in which fume streams. The cylinders are exposed to high vibrational bowing loads and destructive experts that may prompt cylinder disappointment [6]. Consumption can be relieved by picking the correct material for shell and cylinder packs though vibrations can be alleviated by proper structure against the disappointment of cylinders with the goal that stream actuated vibration is viewed as a basic piece of the heat plan [7]. Liquid flexible uncertainty, arbitrary excitation, vortex shedding or intermittent wake shedding, and acoustic reverberation bring about cylinder vibrations in shell-and-cylinder heat exchanger [8]. Among these excitation systems, the most serious vibration component is liquid versatile shakiness, which may cause tube harm following scarcely any long stretches of activity and striking because of stream choppiness causes almost no vibration, which causes tube divider diminishing, due to worrying, such reasons for vibration must be dodged [9]. For firmly single cylinder clusters with a pitch proportion of less than 2 , the vortex shedding deteriorates into broadband ferocious vortexes bringing about tempestuous astounding [10]. Due to cross flow, choppiness increments in tube packages as the liquid streams over the cluster geometry and, in that capacity [11-12], the cylinders are exposed to tempestuous striking [13].

Shell and tube heat exchanger configuration can be optimized by changing the tube length which shows the impact of shell frequencies recurrence [14], tube characteristic recurrence, critical velocity, bundle cross flow, and vortex shedding proportion [15-16]. All the above investigations depend on an essential recurrence 
in particular [17]; there might be an impact of higher modes on vibrations [18]. A detailed investigation was completed for flow prompted vibrations because of liquid flexible precariousness [19], vortex shedding and acoustic reverberation of the cylinder group alongside the essential and higher modes of vibration by changing different boundaries, for example, range, and tube pitch and cross-stream speed [20].

\section{Methodology}

The flow chart of heat exchanger design methodology is given in figure 1 . The first criterion that a heat exchanger should satisfy is the fulfilment of the process requirements; the design specifications may contain all the necessary detailed information on flow rates of streams, operating pressures, pressure drop limitations for streams, temperatures, size, length, and different design constraints such as cost, type of materials, heat exchanger type and arrangements. The heat exchanger originator gives missing data dependent on the encounters, judgment and the prerequisites of the customer.

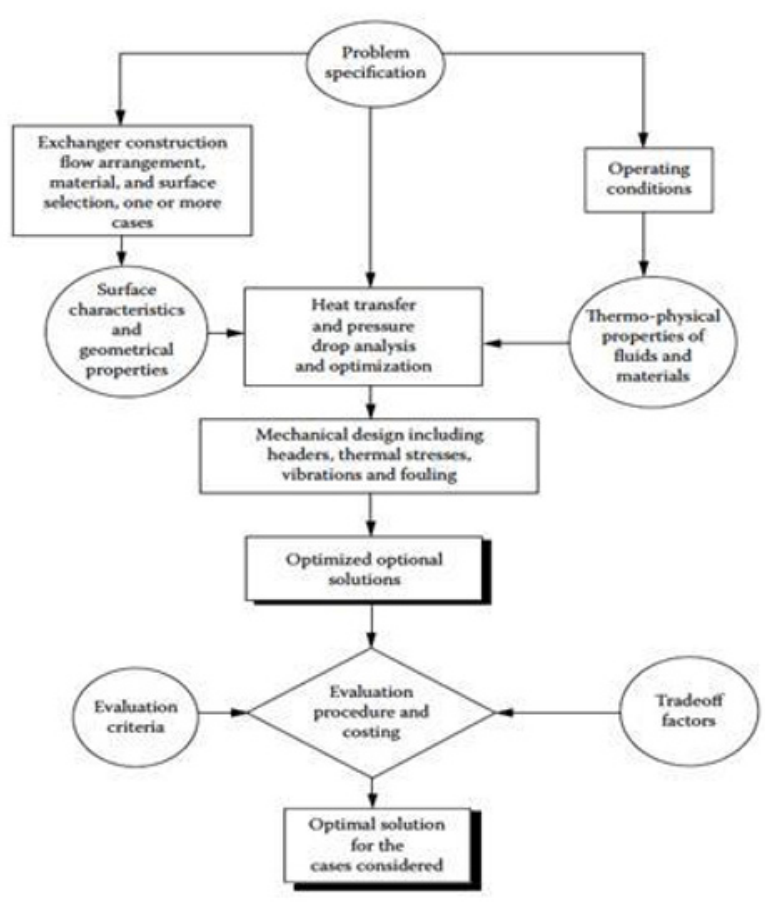

Figure 1 Process of heat exchanger

In view of the difficult details, the exchanger development type, flow arrangement, surface or centre geometry, and materials must be chosen. In the choice of the kind of warmth exchanger, the working weight and temperature levels, maintenance prerequisites, reliability, safety, accessibility and manufacturability of surfaces, and cost must be considered. As discussed in previous sections, heat exchanger thermal design maybe classified as sizing or rating. In the sizing problem, the surface area and heat exchanger dimensions are to be determined; inputs to the sizing problem are as follows: flow rates, inlet temperatures and one outlet temperature, surface geometries, pressure drop limitations, and thermo physical properties of streams and materials. In the rating problem, the heat exchanger already exists or the heat exchanger configuration is selected by approximate sizing. Therefore, inputs to the rating problem are heat exchanger surface geometry and dimensions, fluid flow rates, inlet temperatures, and pressure drop limitations. The fluid outlet temperatures, total heat transferred, and pressure drop for both streams through the heat exchanger are to be calculated in the rating analysis. On the off chance that the rating gives adequate warm execution with pressure drops in the two streams underneath the greatest suitable ones, this warmth exchanger setup might be viewed as an answer for the issue.

It is often possible to find a number of variant configurations that will meet these requirements; then the choice must be made on other criteria, usually the cost of the heat exchanger. In the event that the warmth exchanger chose for rating is discovered to be unsuitable, another structure must be picked for the following rating. The cycle by which one moves from one plan to an additionally fulfilling structure can be called structure adjustment. Rating is the computational process by which one determines the thermal performance and pressure drops for two streams in a completely defined heat exchanger. The selection criteria demand that the heat exchanger with stand the service conditions of the plant environment. Therefore, after thermal design analysis, the mechanical design is carried out, which includes the calculation of plate, tube, shell, and header thicknesses and arrangements. The heat exchanger must resist corrosion by the service and process streams and by the environment; this is mostly a matter of proper material selection. A proper design of inlet and outlet nozzles and connections, supporting materials, location of pressure and temperature measuring devices, and manifolds is to be made.

\subsection{Thermal Design Calculation}

\section{Input parameters:}

\begin{tabular}{|c|l|l|}
\hline $\mathbf{S}$ & Parameters & Value \\
\hline $\mathbf{N}$ & Cooling water inlet temp $\left(\mathrm{T}_{\mathrm{ci}}\right)$ & $12^{\circ} \mathrm{C}$ \\
\hline 2 & $\begin{array}{l}\text { Cooling water outlet temp } \\
\left(\mathrm{T}_{\mathrm{co}}\right)\end{array}$ & $17.5^{\circ} \mathrm{C}$ \\
\hline
\end{tabular}




\begin{tabular}{|c|c|c|}
\hline 3 & Saturation temp ( $\left.\mathrm{T}_{\mathrm{sat}}\right)$ & $22.5^{\circ} \mathrm{C}$ \\
\hline 4 & $\begin{array}{l}\text { Mass flow rate of water vapor } \\
\left(\mathrm{m}_{\mathrm{g}}\right)\end{array}$ & $1.39 \mathrm{Kg} / \mathrm{s}$ \\
\hline \multicolumn{3}{|c|}{ Tube details: } \\
\hline 5 & $\begin{array}{l}\text { Square pitch pattern ( } 45 \\
\text { degree) }\end{array}$ & $3 / 4 "$ OD tubes \\
\hline 6 & Material & $\begin{array}{l}\text { Copper Nickel } \\
(90: 10)\end{array}$ \\
\hline 7 & Thickness of the tube $\left(\mathrm{T}_{\mathrm{w}}\right)$ & $1 \mathrm{~mm}$ \\
\hline 8 & $\begin{array}{l}\text { Thermal conductivity of } \mathrm{Cu}-\mathrm{Ni} \\
\left(\mathrm{K}_{\mathrm{w}}\right)\end{array}$ & $40 \mathrm{~W} / \mathrm{m} . \mathrm{K}$ \\
\hline 9 & Density of Cu-Ni $\left(\rho_{t}\right)$ & $8900 \mathrm{Kg} / \mathrm{m} 3$ \\
\hline 10 & $\begin{array}{l}\text { outside diameter of the tube } \\
\left(d_{o}\right)\end{array}$ & $19 \mathrm{~mm}$ \\
\hline 11 & Inside diameter of the tube $\left(\mathrm{d}_{\mathrm{i}}\right)$ & $17 \mathrm{~mm}$ \\
\hline 12 & $\begin{array}{l}\text { Velocity of water inside the } \\
\text { tube (Vc) }\end{array}$ & $1.2 \mathrm{~m} / \mathrm{s}$ \\
\hline 13 & Noumber of pass & 2 \\
\hline 14 & $\begin{array}{l}\text { Mas flow rate of water vapor } \\
\left(\mathrm{m}_{\mathrm{g}}\right)\end{array}$ & $1.39 \mathrm{Kg} / \mathrm{s}$ \\
\hline 15 & Mean temp is $\left(\mathrm{T}_{\mathrm{co}}+\mathrm{T}_{\mathrm{ci}}\right) / 2$ & $14.75^{0} \mathrm{C}$ \\
\hline
\end{tabular}

Saturated liquid properties@ $T_{\text {sat }}=22.5^{\circ} \mathrm{C}$

$$
\begin{gathered}
\mathrm{P}_{\mathrm{sat}}=0.02895 \mathrm{bar} \\
i_{1}=94.3 \mathrm{KJ} / \mathrm{kg} \\
i_{1 g}=2448.4 \mathrm{KJ} / \mathrm{kg}
\end{gathered}
$$

$$
\begin{gathered}
\mu_{1}=9.52 \times 10^{-4} \mathrm{Ns} / \mathrm{m}^{2} \\
k_{1}=0.581 \mathrm{~W} / \mathrm{mK} \\
\rho_{1}=1026 \mathrm{~kg} / \mathrm{m}^{3}
\end{gathered}
$$

Cooling water properties at mean temperature $\left(14.75^{\circ} \mathrm{C}\right)$

$$
\begin{gathered}
\rho_{c}=999.1 \mathrm{~kg} / \mathrm{m}^{3} \\
K_{c}=0.581 \mathrm{~W} / \mathrm{mK} \\
C_{p c}=4180 \mathrm{~J} / \mathrm{kgK} \\
\mu_{c}=0.0012 \mathrm{Ns} / \mathrm{m}^{2}
\end{gathered}
$$

Prandtl Number $\left(P_{r}\right)=\frac{\mu_{c} \times C_{p c}}{K_{c}}=\frac{0.0012 \times 4180}{0.581}=8.633$

Calculation of mass flow rate cooling water $\left(m_{c}\right)$

$$
Q=m_{c} \times C_{p} \times \Delta T
$$

Where $\Delta T=\left(T_{c o}-T_{c i}\right)=(17-12.5)=5.5^{\circ} \mathrm{C}$

$$
m_{c}=\frac{Q}{C_{p} \times \Delta T}=\frac{3.4 \times 10^{6}}{4180 \times 5.5}=147.89 \mathrm{~kg} / \mathrm{s}
$$

Calculation of number of tubes $\left(N_{T}\right)$

$$
\begin{gathered}
N_{T}=4 \times \frac{m_{c}}{\mu_{c} \times \rho_{c} \times \pi \times d_{i}^{2}} \\
N_{T}=4 \times \frac{147.89}{1.2 \times 999.1 \times 3.14 \times 0.017^{2}}=544 \text { tubes }
\end{gathered}
$$

Since it is a two pass type condenser

$$
N_{T}=2 \times 544=1088 \text { tubes }
$$

Tube side Reynold's number $R_{e}=\frac{\mathrm{V}_{\mathrm{c}} \times \rho_{\mathrm{c}} \times \mathrm{d}_{\mathrm{i}}}{\mu_{\mathrm{c}}}$

$$
R_{e}=\frac{1.2 \times 0.017 \times 999.1}{0.012}=16984.7
$$

Since the $R_{e}>2600$, the flow is said to be turbulent.

Calculation of heat transfer coefficient $\left(h_{i}\right)$ on the tube side 
Pettukhov-Kirillor correlations are used to find the heat transfer coefficient on the tube side

$$
N_{u}=\frac{(\bar{f} / 2) \times R_{e} \times P_{r}}{k+12.7 \sqrt{\bar{f} / 2}\left(P_{r}^{0.67}-1\right)}
$$

$$
\begin{gathered}
\text { Where } k=1.07 \text { and } \bar{f}=\frac{1}{\left(1.58 \ln R_{e}-1.64\right)}= \\
0.006819639 \\
N_{u}=\frac{(0.00682 / 2) \times 16984.7 \times 8.633}{1.07+12.7 \sqrt{0.00682 / 2}\left(8.633^{0.67}-1\right)} \\
N_{u}=144.0143123
\end{gathered}
$$

Heat transfer coefficient at the tube side $\left(h_{i}\right)$

$$
\begin{aligned}
h_{i}=\frac{N_{u} \times K_{c}}{d_{i}}= & \frac{144.0143123 \times 0.581}{0.017} \\
& =4921.90 \mathrm{~W} / \mathrm{m}^{2} \mathrm{~K}
\end{aligned}
$$

Calculation of LMTD

$$
\begin{aligned}
\operatorname{LMTD}=\frac{\left(T_{s a t}-T_{c i}\right)-\left(T_{s a t}-T_{c o}\right)}{\ln \left(\frac{T_{s a t}-T_{c i}}{T_{s a t}-T_{c o}}\right)} \\
=\frac{(22.5-12)-(22.5-17.5)}{\ln \left[\frac{22.5-12}{22.5-17.5}\right]} \\
=7.41^{\circ} \mathrm{C}
\end{aligned}
$$

Calculation of shell side heat transfer coefficient $\left(h_{o}\right)$

$$
\begin{gathered}
R_{t}=R_{f o}+\left[\left(\frac{1}{h_{i}}+R_{f i}\right) \times \frac{d_{o}}{d_{i}}\right]+\frac{t_{w} \times d_{o}}{K_{w} \times D_{m}} \\
\text { We know that } \frac{1}{U}=R_{t}+\frac{1}{h_{o}} \\
D_{m}=\frac{1}{2}\left(d_{i}+d_{o}\right)=\frac{1}{2}(0.017+0.019)=0.018 \mathrm{~m}
\end{gathered}
$$

Fouling resistance factor outside

$$
\left(R_{f o}\right)=0.00088 m^{2} K / W
$$

Fouling resistance factor outside $\left(R_{f i}\right)=$ $0.00088 \mathrm{~m}^{2} \mathrm{~K} / \mathrm{W}$

$$
\begin{aligned}
R_{t}=0.000088+ & {\left[\frac{1}{4921.90}+0.000088\right] \times \frac{0.019}{0.017} } \\
& +\frac{0.001 \times 0.019}{40 \times 0.018}=0.000439818
\end{aligned}
$$

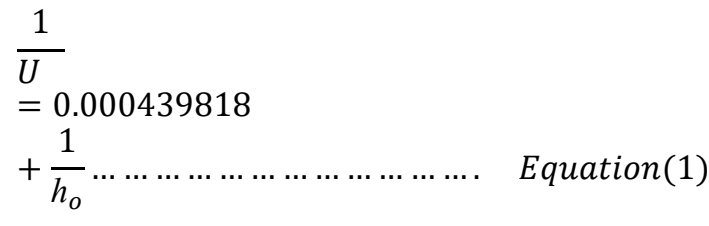

Shell side heat transfer coefficient $\left(h_{o}\right)$

$$
h_{o}=0.728 \times\left[\frac{g \times \rho_{1}^{2} \times i_{1 g} \times k_{1}^{3}}{\mu_{1}+\Delta T_{w} \times d_{o}}\right]^{\frac{1}{4}} \times \frac{1}{(W)^{\frac{1}{6}}}
$$

$=0.728$

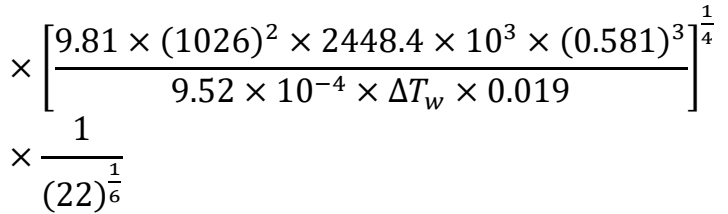

$h_{o}$

$=\frac{9941.290815}{\Delta T_{w}}$ Equation (2)

$$
\begin{gathered}
\Delta T_{w}=\Delta T-R_{t} \ddot{q} \quad " \quad q=U \Delta T \\
\begin{aligned}
\Delta T_{w}=\Delta T-R_{t} U & \Delta T \\
& =\Delta T(1 \\
& \left.-R_{t} U\right) \ldots \ldots \ldots \ldots \ldots E q u a
\end{aligned} \\
\Delta T_{w}=\Delta T(1-0.000439818 \times U
\end{gathered}
$$

Iteration procedure carried out in Table. 1 to calculate $\Delta T_{w i}$ and iteration procedure is carried out in Table 2. To calculate $\Delta T_{w o}$. Calculating $h_{o}$ from equation (2) and $\mathrm{U}$ from equation (1), Recalculate $\Delta T_{w}$ from equation (3). Repeating the calculation from step 2 and continuing iteration until $\mathrm{U}$ converges. The effect of cooling water velocity in design in shown in Table 3.

Inlet side temperature difference $\left(\Delta T_{w i}\right)=(22.5-$ 12) $=10.5^{\circ} \mathrm{C}$

Outlet side temperature difference $\left(\Delta T_{w o}\right)=(22.5-$ 17) $=5.5^{\circ} \mathrm{C}$

Calculation of mean overall heat transfer coefficient $\left(U_{m}\right)$

Converged value of $U_{o i}=1773.61733 \frac{\mathrm{W}}{\mathrm{m}^{2} \mathrm{~K}}$

Converged value of $U_{o o}=1858.165714 \frac{\mathrm{W}}{\mathrm{m}^{2} \mathrm{~K}}$ 
Mean converged value $U_{m}=\frac{(1773.61733+1858.165714)}{2}$

$$
U_{m}=1815.891674 \frac{W}{m^{2} K}
$$

Calculation of heat transfer area $\left(A_{o}\right)$

$$
Q=U_{m} \times A_{o} \times L M T D
$$

\begin{tabular}{|c|c|c|c|}
\hline Iteration no. & $\Delta \mathbf{T}_{\mathbf{w i}}$ & $\mathbf{h}_{\mathbf{o i}}$ & $\mathbf{U}_{\mathbf{o i}}$ \\
\hline 1 & 4 & 7029.554 & 1717.993 \\
\hline 2 & 2.566154624 & 7854.564 & 1763.256 \\
\hline 3 & 2.357124792 & 8023.191 & 1771.615 \\
\hline 4 & 2.318523169 & 8056.38 & 1773.228 \\
\hline 5 & 2.311074192 & 8062.863 & 1773.542 \\
\hline 6 & 2.309624494 & 8064.128 & 1773.603 \\
\hline 7 & 2.309341891 & 8064.375 & 1773.615 \\
\hline 8 & 2.309286783 & 8064.423 & 1773.617 \\
\hline 9 & 2.309276036 & 8064.433 & 1773.618 \\
\hline 10 & 2.30927394 & 8064.434 & 1773.618 \\
\hline 11 & 2.309273532 & 8064.435 & 1773.618 \\
\hline
\end{tabular}

Table 1 Calculation for entry side heat transfer co.eff.

$$
\begin{aligned}
A_{o}=\frac{Q}{U_{m} \times L M T D} & =\frac{3.4 \times 10^{6}}{1815.891674 \times 7.41} \\
& =297.419221 \mathrm{~m}^{2}
\end{aligned}
$$

Calculation of length of the tube (L)

$$
\begin{aligned}
L=\frac{A_{o}}{N_{T} \times \pi \times d_{o}} & =\frac{397.149221}{1088 \times 3.14 \times 0.019} \\
& =4.57786 \mathrm{~m}
\end{aligned}
$$

Calculation of shell diameter $\left(D_{s}\right)$

$$
D_{s}=0.637 \times\left(\frac{C L}{C P T}\right)^{\frac{1}{2}} \times\left[\frac{A_{o} \times(P R)^{2} \times d_{o}}{L}\right]^{\frac{1}{2}}
$$

Incomplete coverage of shell diameter of the tubes (CPT)

For 2 tube pass $=0.9$, Tube pitch $\left(P_{T}\right)=0.0285$ and Pitch ratio $(\mathrm{PR})=1.5$

$$
\begin{gathered}
D_{s}=0.637 \times\left(\frac{1}{0.9}\right)^{\frac{1}{2}} \times\left[\frac{297.149221 \times(1.5)^{2} \times 0.019}{4.577859417}\right]^{\frac{1}{2}} \\
=1.118516279 \mathrm{~m}
\end{gathered}
$$

Calculation of pressure drop on the tube side

$$
\begin{gathered}
\Delta P_{\text {tot }}=\Delta P_{t}+\Delta P_{r} \\
\Delta P_{t}=4 f \frac{L N_{p}}{d_{i}} \times \frac{G^{2}}{2 \rho} \\
N_{p}=\text { No.of pass }=2 \\
f=0.046 R e^{-0.2}=0.046(16984.7)^{-0.2}=0.00655762 \\
G=2 \times 999.1=1198.92 \\
\Delta P_{t}=4 \times 0.00655762 \times\left(\frac{4.57785941 \times 2}{0.017}\right) \\
\times \frac{(1198.92)^{2}}{2 \times 999.1}=10162.28167 \mathrm{~Pa}
\end{gathered}
$$

Calculation of pumping power (P)

$$
\begin{aligned}
\Delta P_{r}=4 N_{p}\left(\frac{\rho V_{c}^{2}}{2}\right) & =4 \times 2 \times \frac{999.1 \times 12^{2}}{2} \\
& =5754.816 \mathrm{~Pa}
\end{aligned}
$$




$$
\begin{gathered}
\Delta P_{\text {tot }}=10162.28167+5754.816=15917.19767 \mathrm{~Pa} \\
=15.917 \mathrm{kPa}
\end{gathered}
$$

\begin{tabular}{|c|c|c|c|}
\hline Iteration no. & $\Delta \mathbf{T}_{\text {wo }}$ & $\mathbf{h}_{\text {oo }}$ & $\mathbf{U}_{\mathbf{o o}}$ \\
\hline 1 & 2 & 8359.596 & 1787.498 \\
\hline 2 & 1.069129527 & 9776.54 & 1844.665 \\
\hline 3 & 0.943414076 & 10087.12 & 1855.444 \\
\hline 4 & 0.919709657 & 10151.5 & 1857.611 \\
\hline 5 & 0.91494448 & 10164.69 & 1858.052 \\
\hline 6 & 0.913974105 & 10167.39 & 1858.143 \\
\hline 7 & 0.913775978 & 10167.94 & 1858.161 \\
\hline 8 & 0.913735503 & 10168.05 & 1858.165 \\
\hline 9 & 0.913727234 & 10168.07 & 1858.166 \\
\hline 10 & 0.913725545 & 10168.08 & 1858.166 \\
\hline 11 & 0.913725199 & 10168.08 & 1858.166 \\
\hline
\end{tabular}

Table 2 Calculation for exit side heat transfer Coefficient

$$
\begin{gathered}
\Delta P_{r}=4 N_{p}\left(\frac{\rho V_{c}^{2}}{2}\right)=4 \times 2 \times \frac{999.1 \times 12^{2}}{2} \\
=5754.816 \mathrm{~Pa} \\
\Delta P_{\text {tot }}=10162.28167+5754.816=15917.19767 \mathrm{~Pa} \\
=15.917 \mathrm{kPa} \\
P=\frac{m_{c} \times \Delta P_{t o t}}{\rho \dot{\eta}_{p}}=\frac{147.89 \times 15917.09767}{999.1 \times 0.60} \\
=3926.84372 \mathrm{~W}
\end{gathered}
$$

Calculation of pumping power $(\mathrm{P})$ 
Table 3 The effect of cooling water velocity in design

\section{Results and Discussions}

\subsection{Overall heat transfer coefficient Vs Tube velocity:}

Figure 2, the below graph shows the variation of overall heat transfer coefficient with respect to the tube velocity. The higher the tube velocity, higher the overall heat transfer coefficient. This linear increment of overall heat transfer coefficient will start decrease from a point 7500 $\mathrm{W} / \mathrm{m}^{2} \mathrm{~K}$ at very high tube velocity $2 \mathrm{~m} / \mathrm{s}$ due to high pressure drop. Such, that an optimum level of tube velocity should be maintained to increase the efficiency of the condenser.

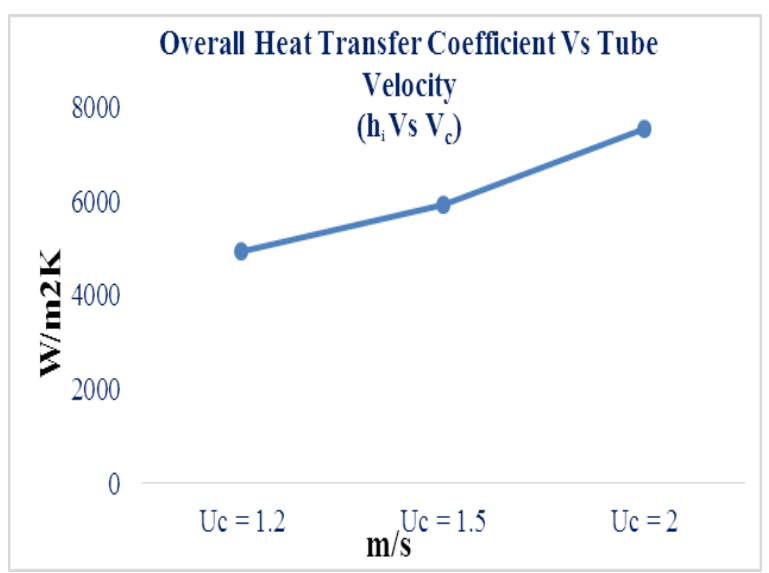

Figure 2 Overall heat transfer coefficient with respect to tube velocity

\subsection{Tube side heat transfer coefficient Vs Tube velocity:}

As shown in figure 3 the below is plotted against tube side heat transfer coefficient and the tube velocity. This graph is similar to the previous graph that the tube side heat transfer coefficient will increase from 1800-2100 $\mathrm{W} / \mathrm{m}^{2} \mathrm{~K}$ with respect to increase in the tube velocity at 2 $\mathrm{m} / \mathrm{s}$. Optimum level of tube velocity should be maintained to avoid more pressure drop inside the tube which ultimately reduces the overall efficiency of the condenser.

\begin{tabular}{|c|c|c|c|}
\hline \multirow[t]{2}{*}{ Parameters } & \multicolumn{3}{|c|}{$\begin{array}{l}\text { Cooling water } \\
\text { velocity }(\mathrm{m} / \mathrm{s})\end{array}$} \\
\hline & $\begin{array}{c}\mathrm{Vc}= \\
1.2\end{array}$ & $\begin{array}{l}\mathrm{Vc}= \\
1.5\end{array}$ & $\begin{array}{c}\mathrm{Vc}= \\
2\end{array}$ \\
\hline No. of tubes $\left(\mathrm{N}_{\mathrm{T}}\right)$ & 1088 & 870 & 654 \\
\hline Reynolds Number(Re) & $\begin{array}{c}16984 . \\
7\end{array}$ & $\begin{array}{c}2123 \\
0.9\end{array}$ & $\begin{array}{c}28307 \\
.83\end{array}$ \\
\hline $\begin{array}{l}\text { Heat transfer coefficient } \\
\left(\mathrm{h}_{\mathrm{i}}\right) \text { on tube side }\end{array}$ & 4921.9 & $\begin{array}{c}5925 . \\
15\end{array}$ & $\begin{array}{c}7535 . \\
384\end{array}$ \\
\hline $\begin{array}{l}\text { heat transfer coefficient } \\
\left(\mathrm{h}_{\mathrm{o}}\right) \text { on shell side }\end{array}$ & 9116.2 & $\begin{array}{c}8912 . \\
79\end{array}$ & $\begin{array}{c}8690 . \\
437\end{array}$ \\
\hline $\begin{array}{l}\text { Overall haet transfer } \\
\text { coefficient }\left(U_{o}\right)\end{array}$ & $\begin{array}{c}1815.8 \\
9\end{array}$ & $\begin{array}{c}1942 . \\
75\end{array}$ & $\begin{array}{c}2095 . \\
268\end{array}$ \\
\hline Heat transfer area $\left(A_{0}\right)$ & 297.14 & $\begin{array}{c}277.7 \\
45\end{array}$ & $\begin{array}{c}257.5 \\
2\end{array}$ \\
\hline Length of the tube (L) & 4.57 & 5.35 & 6.6 \\
\hline $\begin{array}{l}\text { Diameter of the shell } \\
\left(D_{s}\right)\end{array}$ & 1.11 & 1.002 & 0.867 \\
\hline Pressure drop $\left(\Delta \mathrm{P}_{\mathrm{tot}}\right)$ & $\begin{array}{c}15917 . \\
1\end{array}$ & $\begin{array}{c}2674 \\
2.4\end{array}$ & $\begin{array}{c}52732 \\
.48\end{array}$ \\
\hline Pumping power $(\mathrm{P})$ & $\begin{array}{c}3926.8 \\
4\end{array}$ & $\begin{array}{c}6597 . \\
52\end{array}$ & $\begin{array}{c}13009 \\
.42\end{array}$ \\
\hline
\end{tabular}




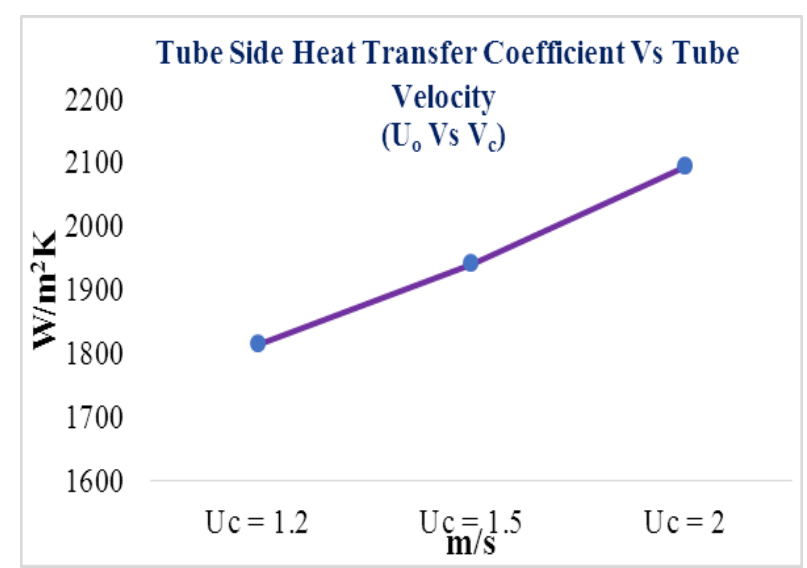

Figure 3 Tube side heat transfer coefficient with respect to tube velocity

\subsection{Total pressure drop Vs Tube velocity:}

As discussed earlier that the total pressure drop will increase with respect to the tube velocity as show in figure 4. A condenser should be designed within the respective pressure drop above which will affect the efficiency of the system. The above graph explains clearly that higher the tube velocity higher the pressure drop, thus an optimum tube velocity should be maintained inside the condenser.

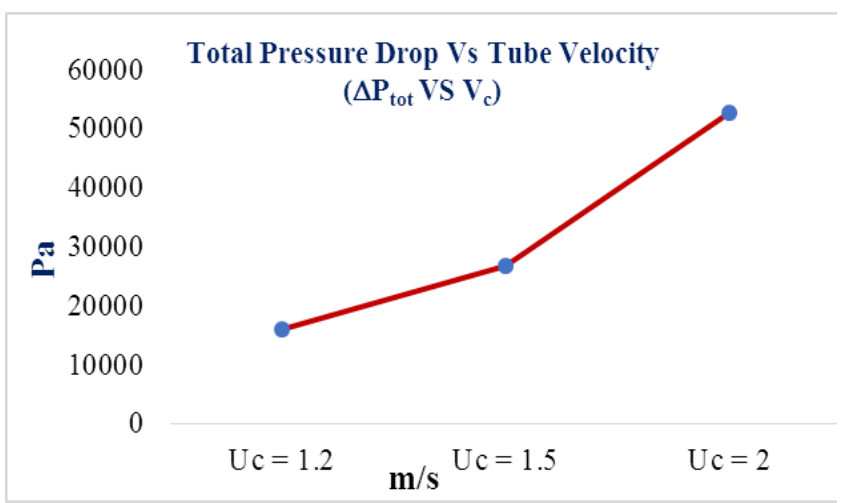

Figure 4 Total pressure drop with respect to tube velocity

\subsection{Mass flow rate of cooling water Vs Total pressure drop:}

Likewise, as discussed in the above graph the increase in the mass flow rate of cooling water also increases the pressure drop in the tube as shown in figure 5 . The design of the condenser is to be done within the specified pressure drop limits such that the pressure drop in the tube should also be considered while fixing the mass flow rate of cooling water.

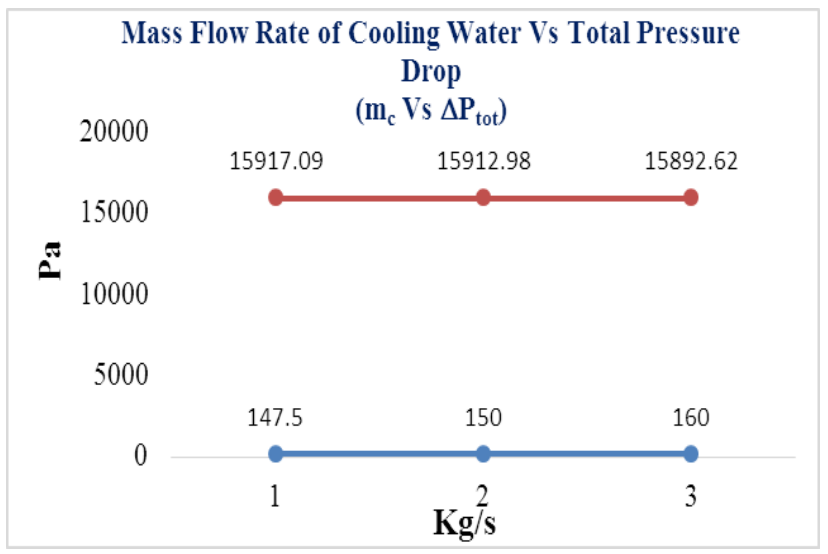

Figure 5 Mass flow rate of cooling water with respect to total pressure drop

\subsection{Mass flow rate of cooling water Vs Pumping power:}

The pumping power gets increased appropriately with the increase in the mass flow rate of the cooling water as shown in figure 6 . The higher the capacity of the pump higher the cost thus, pumping power for the cooling water circuit should be considered while fixing the mass flow rate of cooling water and also the cost of the pump should be economical.

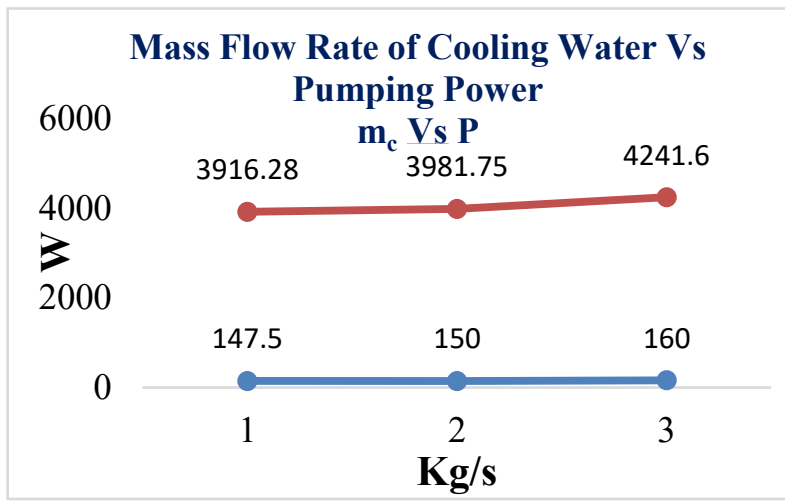

Figure 6 Mass flow rate of cooling water with respect to pumping power

\subsection{Parameters with respect to velocity:}

The pumping power gets increased appropriately with the increase in the velocity of the cooling water as shown in figure 7 . The capacity of the parameters, overall heat transfer coefficient of cooling water circuit should be considered while fixing the mass flow rate of cooling water and also the cost of the pump should be economical. 


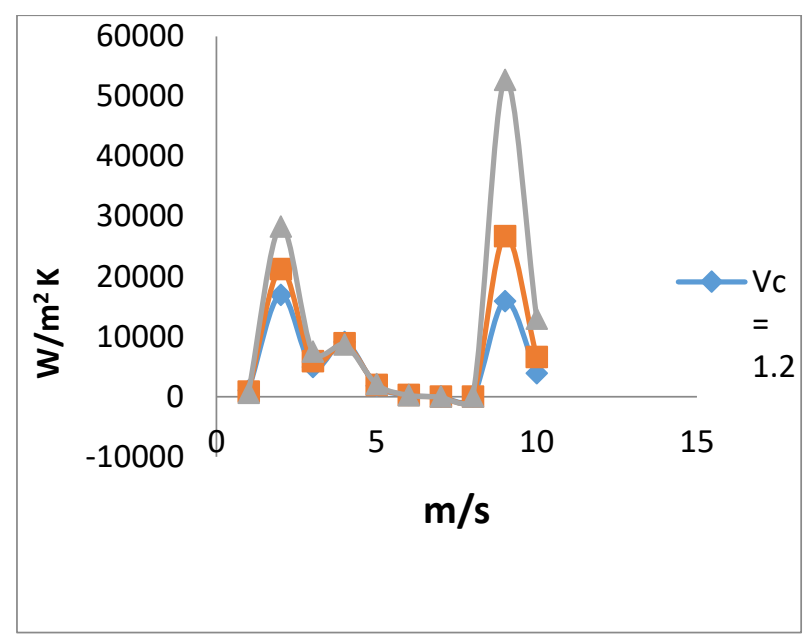

Figure 7 Parameters with respect to velocity

\section{Conclusion}

Using the proposed standards and design procedures shell and tube condenser is designed in order to satisfy the primary requirements. Analyses of the design are also done by the various critical factors, which greatly influence the heat transfer properties in the shell and tube condenser. As a novelty of the work a micro fin tubes are used in the above designed condenser successfully which will increase the heat transfer rate by a greater extent than the use of smooth tube. In addition to that various techniques are proposed for the alternatives of smooth tubes in condenser which will also increase the heat transfer rate.

Conflict of Interest: The authors declare that there are no conflict of interest

\section{References}

1. Gawande, Shravan H, Appasaheb A Keste, Laxman G Navale, Milindkumar R Nandgaonkar, Vaishali J Sonawane, and Umesh B Ubarhande "Design optimization of shell and tube heat exchanger by vibration analysis." Review of. Modern Mechanical Engineering 1 (1):6-(2011).

2. Goyder, HGD. "Flow-induced vibration in heat exchangers." Review of. Chemical Engineering Research and Design 80 (3):226-32-(2002.)

3. Jahangiri, MR. "Failure Analysis of Type 304 Stainless Steel Tubes in an Energy Production Plant Heat Exchangers." Review of. Journal of pressure vessel technology 133 (6)-( 2011.)

4. Thulukkanam, Kuppan. Heat exchanger design handbook: CRC press-(2013.)

5. Pettigrew, MJ, and CE Taylor,-"Vibration analysis of shell-and-tube heat exchangers: an overview-Part 1: flow, damping, fluidelastic instability." Review of. Journal of Fluids and Structures 18 (5):469-83,(2003.) 6. Pettigrew, MJ, and CE Taylor. "Vibration analysis of shell-and-tube heat exchangers: an overview-Part 2: vibration response, fretting-wear, guidelines." Review of. Journal of Fluids and Structures 18 (5):485500,(2003.)

7. Polak, DR, and DS Weaver. "Vortex shedding in normal triangular tube arrays." Review of. Journal of Fluids and Structures 9 (1):1-17. (1995.)

8. Shah, Ramesh K, and Dusan P Sekulic Fundamentals of heat exchanger design: John Wiley \& Sons,(2003)

9. Siddique, M, A-RA Khaled, NI Abdulhafiz, and AY Boukhary "Recent advances in heat transfer enhancements: a review report." Review of. International Journal of Chemical Engineering 2010.

10. Balaji, D, Raju Abraham, SVS Phani Kumar, and MV Ramana Murthy. "Experimental and comparative study of a sea water-cooled surface condenser of LTTD plant with HTRI and Kern method." Review of. Desalination and Water Treatment 57 (41):1954056.(2010)

11. Sapali, SN, and PRADEEP A Patil. "Two-phase condensation heat transfer coefficients and pressure drops of R404a for different condensing temperatures in a smooth and micro-fin tube." Review of. International Journal of Engineering Science and Technology 1 (2):43-58.( 2009)

12. Kalendar, A, T Galal, A Al-Saftawi, M Zedan, SS Karar, and R El-shiaty. "Heat Transfer Characterization of Enhanced Condenser Tubes; Comparison with Conventional Type, Utilizing a Developed Design for Test Apparatus." Review of. Journal of Applied Mechanical Engineering:2168-9873.(2012)

13. Mukherjee, Rajiv "Effectively design shell-and-tube heat exchangers." Review of. Chemical Engineering Progress 94 (2):21-37,(1998).

14. Venkatesan, G, S Iniyan, and Purnima Jalihal "A desalination method utilising low-grade waste heat energy." Review of. Desalination and Water Treatment 56 (8):2037-45.(2015).

15. Venkatesan, G, S Iniyan, and Ranko Goic "A prototype flash cooling desalination system using cooling water effluents." Review of. International journal of energy research 37 (9):1132-40,(2013)

16. Soltan, B Khalifeh, M Saffar-Avval, and E Damangir "Minimizing capital and operating costs of shell and tube condensers using optimum baffle spacing." Review of. Applied Thermal Engineering 24 (17-18):2801-10,(2004).

17. Allen, Benoît, and Louis Gosselin, "Optimal geometry and flow arrangement for minimizing the cost of shell-and-tube condensers." Review of. International journal of energy research 32 (10):958-69,(2008).

18. Yang, Jie, Aiwu Fan, Wei Liu, and Anthony M Jacobi. "Optimization of shell-and-tube heat exchangers conforming to TEMA standards with designs motivated by constructal theory." Review of. Energy conversion and management 78:468-76,(2014).

19. Fettaka, Salim, Jules Thibault, and Yash Gupta. "Design of shell-and-tube heat exchangers using 
multiobjective optimization." Review of. International Journal of Heat and Mass Transfer 60:343-54,(2013).

20. Selbaş, Resat, Önder Kızılkan, and Marcus Reppich. "A new design approach for shell-and-tube heat exchangers using genetic algorithms from economic point of view." Review of. Chemical Engineering and Processing: Process Intensification 45 (4):268-75, (2006). 